\title{
It takes a seasoned bird to be a good listener: communication between the sexes
}

Eliot A. Brenowitz

Departments of Psychology and Biology, Virginia Merrill Bloedel Hearing Research Center, University of Washington, Box 351525, Seattle, WA 98195, USA

Luke Remage-Healey

Neuroscience and Behavior Program, Center for Neuroendocrine Studies, Department of Psychological and Brain Sciences, University of Massachusetts, Amherst, Massachusetts 01003, USA

Corresponding author: Eliot Brenowitz, eliotb@uw.edu, 206-543-8534 (phone), 206-685-3157 (FAX) Department of Psychology, Box 351525, University of Washington, Seattle, WA, USA 98195

\section{Abstract:}

Birds commonly use sound for communication between the sexes. In many songbird species, only males sing and there are pronounced sex differences in the neural song control circuits. By contrast, the auditory circuitry is largely similar in males and females. Both sexes learn to recognize vocalizations heard as juveniles and this shapes auditory response selectivity. Mating vocalizations are restricted to the breeding season, when sex steroid levels are elevated. Auditory cells, from the ear to the cortex, are hormone sensitive. Estrogens are synthesized in the brain and can modulate the activity of auditory neurons. In species that breed seasonally, elevated levels of estradiol in females transiently enhance their auditory responses to conspecific vocalizations, resulting in sex differences in audition. 


\section{Introduction}

The use of sound for communication between the sexes is a prominent trait of birds. Sounds are commonly used for attracting and recognizing mates. Birds present an interesting model for studies of sex differences in vocal communication for several reasons. 1) Among the 9000 species of birds there is extensive diversity in the degree of sex differences in vocal behavior. 2) Species-specific vocalizations in songbirds and parrots are typically developed by juveniles through sensorimotor learning. The auditory selectivity of cortical neurons to those sounds is also shaped by learning. 3) Vocalizations used for mate attraction are usually restricted to the breeding season. Sex steroid hormones are elevated in breeding birds. Auditory cells, from the ear to the cortex, often have steroid receptors and are therefore sensitive to these hormones. Emerging research shows that estrogens can enhance auditory responses to conspecific signals. This raises the hypothesis that pronounced sex differences in neural responses, when they occur, are only present in breeding birds, caused by transient high estrogen levels in the blood and brain of females. Here we review the evidence for sex differences in vocal production and perception, and the contribution of learning and hormones to sex differences in audition. We will focus on songbirds since most of the relevant research has been done on this group.

\section{Sex differences in song learning and production}

There is great diversity in sexual patterns of song learning and production among the 4000 species of songbirds, from species in which only males sing to those in which both sexes sing in complex vocal duets [1-3]. Song learning has been studied mostly in species where only males sing. Even females that do not sing may learn to discriminate songs of different males. Different behavioral assays show that females of several species prefer songs heard as juveniles, as do males [reviewed in 4], which demonstrates that early exposure to song is important for song recognition in both sexes, even for those species in which only males learn to produce song [5]. The sexes may differ, however, in what aspects of 
perception are learned. Adult male Zebra Finches (Taeniopygia guttata) placed in isolation during the juvenile sensitive period for song learning fail to show selective neural responses to conspecific songs or calls, as measured by magnetic resonance imaging or event-related potentials. By contrast, female finches that were similarly isolated as juveniles do show selective neural responses to conspecific vocalizations [6]. The behavioral preference of adult females for song features heard as juveniles shows, however, that while they may hatch with a broad filter for conspecific song, experience sharpens their discrimination among the songs of individual males.

In species where females learn to sing there may be sex differences in different aspects of learning. Female Northern Cardinals (Cardinalis cardinalis) learn the same number of songs as males. The sensitive phase for memorizing songs starts at the same age in males and females, but ends much earlier in females [7]. This difference allows females to selectively learn the songs in their natal area, whereas males continue to learn after they disperse to new areas. Females raised in acoustic isolation do not learn to sing normally, whereas isolated males can improvise de novo normal cardinal song.

\section{Sex differences in behavioral auditory perception}

Song discrimination has been measured with various behavioral assays. Male red-winged blackbirds (Agelaius phoeniceus) respond aggressively to an imitation of redwing song by a Northern Mockingbird (Mimus polyglottos). Female redwings, however, do not perform a copulation solicitation display in response to this imitation $[8,9]$. Male and female Zebra Finches both make "long calls" (learned in males but not females) preferentially in response to female long calls, but discriminate using different acoustic components of these calls [10-12]. Females rely on call duration, whereas males make a categorical discrimination based on the absence of frequency modulation [10]. There is a strong motivational aspect to these behavioral measures, which makes it challenging to determine perceptual limits. 
Operant training procedures isolate sensory ability from motivational factors and have been used to examine psychoacoustics in a broad range of birds (e.g., canaries, pigeons, owls, chickens, parakeets, hawks) [reviewed in 13]. These methods are generally used either to measure thresholds for detection or discrimination, or to measure the discrimination among two or more sounds $[14,15]$. Few psychoacoustic studies have directly compared hearing in conspecific male and female birds. Dooling et al. [16] showed that male and female parakeets (Melopsittacus undulatus) differed in how they categorized the same set of conspecific vocalizations. Female Zebra Finches required more operant trials to learn to discriminate between two conspecific songs than did males [17].

Changes in heart rate have also been used to measure perception. Ikebuchi et al. [14] found that male Bengalese finches (Lonchura striata) did not differentiate between songs of other individual males, but females did distinguish among them. Male and female Chiffchaffs (Phylloscopus collybita) did not differ in their heart rate response to conspecific songs [18]. Both sexes of European Robins (Turdus merula) increased heart rate more to conspecific than heterospecific song, and this increase lasted longer in males [19].

The overall impression from these operant and heart rate studies is that there are not substantial sex differences in behavioral song discrimination (R. Dooling, G. Klump, personal communication). A caveat to this conclusion, however, is that birds used in captive studies are likely not to be in breeding condition, and females therefore would not experience enhanced auditory responses due to high levels of estrogenic hormones in the plasma and brain (see below). Consistent with this suggestion, Zebra Finches required more operant trials to reach criterion in the winter than summer [17]. Future research should explicitly compare hearing in breeding and nonbreeding conspecific males and females, especially in species in which females sing [e.g., 20]. 


\section{Sex differences in brainstem auditory responses}

Peripheral auditory function can be evaluated using the auditory brainstem response (ABR), a shortlatency evoked potential typically emitted $10-15 \mathrm{~ms}$ after the presentation of an auditory stimulus. Sex differences in brainstem auditory function were observed using ABRs in the Brown-headed Cowbird (Molothrus ater) [21]. Female cowbirds are brood parasites and lay their eggs in the nests of other species. They may detect their specific host species by eavesdropping on their songs, which typically have peak energy at $2-4 \mathrm{kHz}$. Male cowbird songs, by contrast, have energy above $4 \mathrm{kHz}$. Females are much more sensitive (by ca. $15 \mathrm{~dB}$ ), and have better frequency discrimination, at $2-4 \mathrm{kHz}$ than males, which may improve their ability to detect and localize the species they parasitize from a distance. In Zebra Finches, tones and clicks evoked higher amplitude and shorter latency peaks for the early ABR waves in females, suggesting more synchronous activity [22]. A study of White-crowned Sparrows (Zonotrichia leucophrys), however, found that males and females did not differ in ABR thresholds, peak latencies, or frequency tuning [23]. Thresholds were elevated and latencies delayed in both sexes by exposure to breeding-typical levels of steroid sex hormones (testosterone in males, 17ß-estradiol (E2) in females).

\section{Sex differences in central auditory processing}

Studies of neural activity in telencephalic auditory nuclei of songbirds (see Figure 1) show that males and females are largely similar, with only subtle differences [reviewed in 24]. In the caudomedial nidopallium (NCM, analogous to mammalian A2) and other auditory areas, neurons in female and male Zebra Finches respond similarly to familiar stimuli (e.g., tutor songs). By contrast, NCM in females shows diminished response magnitude and shallower rates of stimulus adaptation to novel song stimuli [25]. In male finches, neurons in the adjacent caudomesopallium (CM, also analogous to mammalian A2) respond selectively to conspecific songs over white noise [26], whereas female CM lacks this response 
selectivity [27]. These observations suggest that higher-order song processing regions may encode stimulus novelty and perhaps social relevance differently in the sexes, though the differences are subtle. These neuronal response differences in finches may reflect the divergence in behavioral contexts of auditory processing between males, who use songs for mate attraction and inter-male aggression, and females, who use songs to choose a mate.

Studies examining immediate-early gene (IEG) expression profiles in developing songbirds show some subtle but quantifiable early sex differences. As early as 30 days post-hatch, IEG expression in both NCM and CM differ between male and female Zebra Finches. Conspecific song upregulates the IEG FOS in both of these auditory regions in females but not in males, whereas conspecific song-induced EGR1 upregulation occurs in both regions in males but not in females [28]. These sex differences are no longer present at 45 days post-hatch [29] or in adulthood (> 100 days) [30]. This brief developmental period of sex difference aligns with the time of intensive sensorimotor song learning in males (up to ca.35 days post-hatch), and indicates that there are early sex-specific genetic mechanisms operating in the auditory forebrain. In adult finches, in general there are no sex differences in song-induced IEG responses in the auditory forebrain [31,32]. The one exception is greater EGR1 expression in CM in response to conspecific male vocalizations in adult female finches $[10,33]$. The functional consequences of these sex differences in IEG expression are not yet clear, but are consistent with the general subtlety of sexspecific response patterns in the auditory pathway.

\section{Hormone effects on auditory responses}

Steroid hormones influence activity in auditory regions and contribute to sex differences in response patterns in songbirds. Neurons within the auditory forebrain, including NCM, CM, and also the thalamic region IC (central nucleus of the inferior colliculus, see [34]; Figure 1) exhibit elevated EGR1 induction in response to song following treatment with estradiol implants $[35,36]$. In NCM and CM this is due to 
decreased response to simple stimuli like tones, compared to complex stimuli like song, and this increases the selectivity for biologically relevant sounds. The degree of sex-specificity for hormonal influences on neural activity in auditory regions is an active topic of investigation. The hormonedependent IEG selectivity for song stimuli over tone stimuli appears to occur only in the female auditory forebrain, since hormone treatment of males did not alter stimulus selectivity in EGR-1 responsiveness [37]. Similarly, Caras et al. [38,39] showed that estrogen increased the sensitivity and response strength of spike-timing neurons in the primary telencephalic auditory region field L (Figure 1 ) to tones and conspecific songs in breeding female, but not male, White-crowned Sparrows. These findings support the general idea that prolonged increases in circulating hormone levels that bring female birds into breeding condition also produce sex-specific changes in auditory responsiveness.

Sex differences in audition have also been examined by measurement and manipulation of local steroid hormone levels in songbird brain. In vivo microdialysis measurement in Zebra Finches has shown that steroid levels in the brain can rapidly fluctuate, analogous to neuromodulators. In cases where baseline neuroestradiol levels in NCM were directly compared between male and female finches, however, no difference was detected [40]. The auditory NCM therefore appears to have a similar neuroestrogen 'set point' for baseline functions in adulthood, and in each sex the neuroestrogen levels are elevated in NCM compared to nearby brain regions that exhibit lower expression of the estrogen synthesis enzyme, aromatase [24].

Similarly, the elevation in neuroestradiol levels within NCM in response to auditory stimulation is similar in magnitude in male and female finches $[40,41]$. Furthermore, no qualitative difference exists between sexes in the acute actions of E2 on enhancing the neuronal encoding of songs in NCM [40]. This is generally consistent with a lack of sex differences in the NCM of finches in the expression of any of the major classical estrogen receptors [42,43], as well as non-classical estrogen receptors [44]. The acute 
estrogen signaling that regulates auditory function in the Zebra Finch NCM thus does not appear to differ qualitatively or quantitatively between males and females.

The telencephalic song control circuits are sexually dimorphic in morphology in Zebra Finches, and the masculinization of the song system and singing behavior itself is partially dependent on estrogens [45-48]. However, when directly examining neuroestradiol levels within the auditory forebrain, no differences were detected between males and females during the critical period for masculinization [49]. Therefore, endogenous estrogens cannot solely account for masculinization, and the role of other brain-derived steroids, as well as genetic factors, in regulating sexually differentiated behaviors in songbirds should be considered.

\section{Conclusions:}

The neural circuit that regulates the motor production of learned species-specific vocalizations in songbirds provides one of the most pronounced examples of sexual dimorphism in the vertebrate brain. In species where only males sing, such as the Zebra Finch, there are male-biased sex differences in morphological, genetic, neurochemical, and neurophysiological traits. When we look at the auditory system of birds, however, the impression is one of overall similarity between the sexes, especially in nonbreeding birds. What sex differences there are in auditory function tend to be more subtle than are seen in the song production circuitry. The greatest sex differences in auditory responses are seen in seasonally-breeding birds, and seem to result from the elevated levels of estradiol present in the brain of females. The contrast between pronounced sex differences in the song production circuits and similarity between the sexes in the auditory system likely reflects that fact that song detection and discrimination are important for both males and females, even if only males sing in a given species. Male song has its greatest behavioral salience for females when they are breeding, and estradiol is a seasonal internal cue that provides an effective way of enhancing auditory function at that critical time 
of year. Future research should address the cellular and molecular mechanisms of the hormonal effects on auditory responses.

\section{Acknowledgements:}

We thank Daniel Vahaba for making the figure, Bob Dooling and Georg Klump for helpful discussion, and the editors for their comments. This work was supported by NIH MH53032 (EAB), NS075331 (EAB), NS082179 (LRH), and NSF IOS1354906 (LRH). 


\section{Figure caption:}

Figure 1. The neural circuits for auditory processing, song production, and sensorimotor learning in songbirds.

The ascending pathway that processes auditory information including song is shown in blue. Auditory output from the inner ear is conveyed by the VIIIth nerve to the cochlear nuclei in the brain stem (not shown), and then to inferior colliculus (IC) in the midbrain [34]. IC projects to the nucleus ovoidalis (Ov) complex in the thalamus. Ov projects to the telencephalic field $L$ complex $(\mathrm{LI}, \mathrm{L} 2, \mathrm{~L} 3$ ) (analogous to mammalian A1) and the caudomedial nidopallium (NCM, analogous to mammalian A2). The field L complex connects reciprocally to the caudomesopallium (CM, analogous to mammalian A2). NCM and CM are also reciprocally connected. There are sex differences in gene expression in NCM of Zebra Finches. Females show higher levels of calbindin expression, and males have more fibers in NCM that label for the estrogen synthesizing enzyme aromatase [50].

The nuclei in green represent the descending motor pathway for song production, which receives premotor information from the nuclei in purple. It originates in nucleus uvaeformis (Uva) in the thalamus and includes projections from HVC (proper name) to the robust nucleus of the acropallium (RA) in the telencephalon, and from RA to medullary nXIIts, which innervates the muscles of the soundproducing organ, the syrinx, and the brainstem respiratory pre-motor nuclei.

An anterior forebrain pathway (AFP) important for song learning and vocal variability is shown in red. The AFP includes HVC, area X in the striatum, the dorso-lateral division of the medial thalamus (DLM, not shown), lateral magnocellular nucleus of the anterior nidopallium (LMAN), and RA; it is analogous to the mammalian basal ganglia-thalamocortical circuit [51]. The AFP is essential for song learning, for the motor production of song in juveniles [52], and for adult song variability [reviewed in 53]. 
The song control system receives auditory input at multiple levels. CM projects to ventral HVC, and to the area surrounding RA (not shown). CM also projects to the interfacial nucleus of the nidopallium (NIf), which appears to provide the major auditory input to the song control circuits (not shown) [reviewed in 54,55]. Neurons within HVC, RA, IMAN, area X, and NIf respond to acoustic stimuli. Some neurons within each of these nuclei respond maximally, although not exclusively, to presentation of the bird's own song (BOS), consistent with their primary role in sensorimotor integration. 


\section{References and recommended reading}

Papers of particular interest, published within the period of review, have been highlighted as:

* of special interest

** of outstanding interest

1. Beecher MD, Brenowitz EA: Functional aspects of song learning in the songbirds. Trends Ecol. Evol. 2005, 20:143-149.

2. Brenowitz EA, Beecher MD: Song learning in birds: diversity and plasticity, opportunities and challenges. Trends Neurosci 2005, 28:127-132.

*3. Fortune ES, Rodríguez C, Li D, Ball GF, Coleman MJ: Neural Mechanisms for the Coordination of Duet Singing in Wrens. Science 2011, 334:666-670.

Auditory activity in HVC was recorded from wild-caught male and female Bay Wrens, a neotropical species in which both sexes sing duets. Neurons in both sexes responded best to the combined male and female duet than to either sex's notes alone.

4. Catchpole CK, Slater PJB: Bird song: Biological themes and variations edn Second. Cambridge, U.K: Cambridge University Press; 2008.

*5. Riebel K, Smallegange IM, Terpstra NJ, Bolhuis JJ: Sexual equality in zebra finch song preference: evidence for a dissociation between song recognition and production learning. Proceedings of the Royal Society B: Biological Sciences 2002, 269:729-733.

Female Zebra Finches do not sing but choose to hear playback of their father's song in an operant task. The results show that fine auditory discrimination is learned and uncoupled from motor learning to sing. *6. Maul KK, Voss HU, Parra LC, Salgado-Commissariat D, Ballon D, Tchernichovski O, Helekar SA: The development of stimulus-specific auditory responses requires song exposure in male but not female zebra finches. Developmental Neurobiology 2010, 70:28-40. 
This study used MRI to show that female Zebra Finches, but not males, raised in isolation showed enhanced forebrain auditory responses to conspecific songs and calls. Females are hatched with a coarse filter for conspecific vocalizations, but early learning fine-tunes discrimination among the songs of different males.

7. Yamaguchi A: Sex differences in vocal learning in birds. Nature 2001, 411:257-258.

8. Brenowitz $\mathrm{E}$ : The contribution of temporal song cues to species recognition in the red-winged blackbird. Anim. Behav 1983, 31:1116-1127.

9. Searcy W, Brenowitz EA: Sexual differences in species recognition of avian song. Nature 1988, 332:152-154.

10. Gobes SMH, ter Haar SM, Vignal C, Vergne AL, Mathevon N, Bolhuis JJ: Differential responsiveness in brain and behavior to sexually dimorphic long calls in male and female zebra finches. The Journal of Comparative Neurology 2009, 516:312-320.

11. Vicario DS: Using learned calls to study sensory-motor integration in songbirds. Ann N Y Acad Sci $2004,1016: 246-262$.

12. Vicario DS, Naqvi NH, Raksin JN: Behavioral discrimination of sexually dimorphic calls by male zebra finches requires an intact vocal motor pathway. J Neurobiol 2001, 47:109-120.

13. Moss CF, Carr CE: Comparative Psychology of Audition. In Handbook of Psychology. Edited by: John Wiley \& Sons, Inc.; 2003.

14. Ikebuchi M, Futamatsu M, Okanoya K: Sex differences in song perception in Bengalese finches measured by the cardiac response. Animal Behaviour 2003, 65:123-130.

15. Dooling RJ, Hulse SH: The Comparative Psychology of Audition: Perceiving Complex Sounds. Hillsdale, NJ: Erlbaum; 1989. 
16. Dooling RJ, Park TJ, Brown SD, Okanoya K: Perception of species-specific vocalizations by isolatereared budgerigars (Melopsittacus undulatus). International Journal of Comparative Psychology 1990, 4:57-78.

17. Cynx J, Nottebohm F: Testosterone facilitates some conspecific song discriminations in castrated zebra finches (Taeniopygia guttata). Proc Natl Acad Sci U S A 1992, 89:1376-1378.

18. Zimmer UE: Birds React to Playback of Recorded Songs by Heart Rate Alteration. Zeitschrift für Tierpsychologie 1982, 58:25-30.

19. Diehl P, Helb H-W: Radiotelemetric monitoring of heart-rate responses to song playback in blackbirds (Turdus merula). Behavioral Ecology and Sociobiology 1986, 18:213-219.

20. Caras ML: Estrogenic modulation of auditory processing: A vertebrate comparison. Frontiers in Neuroendocrinology 2013, 34:285-299.

*21. Gall M, Lucas J: Sex differences in auditory filters of brown-headed cowbirds (Molothrus ater). Journal of Comparative Physiology A 2010, 196:559-567.

Female cowbirds lay their eggs in other species' nests. Auditory brainstem responses show that female cowbirds are much more sensitive than males to the frequencies found in the songs of their host species.

*22. Noirot IC, Adler HJ, Cornil CA, Harada N, Dooling RJ, Balthazart J, Ball GF: Presence of aromatase and estrogen receptor alpha in the inner ear of zebra finches. Hear Res 2009, 252:49-55.

The first study to show hormone sensitivity of the inner ear in songbirds. In males and females both the estrogen synthetase enzyme aromatase and estrogen receptors were found in inner ear hair cells.

23. Caras M, Brenowitz E, Rubel E: Peripheral auditory processing changes seasonally in Gambel's white-crowned sparrow. Journal of Comparative Physiology A: Neuroethology, Sensory, Neural, and Behavioral Physiology 2010, 196:581-599. 
24. Krentzel AA, Remage-Healey L: Sex differences and rapid estrogen signaling: A look at songbird audition. Frontiers in Neuroendocrinology 2015, 38:37-49.

*25. Yoder KM, Phan ML, Lu K, Vicario DS: He hears, she hears: Are there sex differences in auditory processing? Developmental Neurobiology 2015, 75:302-314.

Multiunit recordings from NCM in Zebra Finches show stronger responses in both sexes to famililar song with which birds were turored as juveniles, than to novel finch songs, showing a role of learning in auditory discrimination. Response magnitude and adaptation rate to familiar song were reduced in female NCM compared with males.

26. Grace JA, Amin N, Singh NC, Theunissen FE: Selectivity for conspecific song in the zebra finch auditory forebrain. J Neurophysiol 2003, 89:472-487.

27. Hauber M, Cassey P, Woolley SN, Theunissen F: Neurophysiological response selectivity for conspecific songs over synthetic sounds in the auditory forebrain of non-singing female songbirds. Journal of Comparative Physiology A 2007, 193:765-774.

*28. Bailey DJ, Wade J: Differential expression of the immediate early genes FOS and ZENK following auditory stimulation in the juvenile male and female zebra finch. Molecular Brain Research 2003, 116:147-154. There was a pronounced sex difference in expression of immediate early genes FOS vs. $E G R-1$ in the auditory forebrain of Zebra Finches in response to song playback treatment during the critical period for sensory song learning. This sex difference was lost later in development.

29. Bailey DJ, Wade J: FOS and ZENK responses in 45-day-old zebra finches vary with auditory stimulus and brain region, but not sex. Behavioural Brain Research 2005, 162:108-115.

30. Mello CV, Vicario DS, Clayton DF: Song presentation induces gene expression in the songbird forebrain. Proc Natl Acad Sci U S A 1992, 89:6818-6822. 
31. Tomaszycki M, Peabody C, Replogle K, Clayton D, Tempelman R, Wade J: Sexual differentiation of the zebra finch song system: potential roles for sex chromosome genes. BMC Neuroscience 2009, 10:24.

32. Duffy DL, Bentley GE, Ball GF: Does sex or photoperiodic condition influence ZENK induction in response to song in European starlings? Brain research 1999, 844:78-82.

33. Avey M, Phillmore L, Macdougallshackleton S: Immediate early gene expression following exposure to acoustic and visual components of courtship in zebra finches. Behavioural Brain Research 2005, 165:247-253.

34. Woolley SMN, Portfors CV: Conserved mechanisms of vocalization coding in mammalian and songbird auditory midbrain. Hearing Research 2013, 305:45-56.

35. Maney DL, Cho E, Goode CT: Estrogen-dependent selectivity of genomic responses to birdsong. European Journal of Neuroscience 2006, 23:1523-1529.

**36. Sanford SE, Lange HS, Maney DL: Topography of Estradiol-Modulated Genomic Responses in the Songbird Auditory Forebrain. Developmental Neurobiology 2010, 70:73-86.

An important study showing that the auditory region NCM of female White-throated Sparrows has subdomains that respond differently to song, as well as to seasonally elevated estrogens.

37. Earp SE, Maney DL: Birdsong: Is It Music to Their Ears? Frontiers in Evolutionary Neuroscience 2012, 4:14.

**38. Caras ML, O'Brien M, Brenowitz EA, Rubel EW: Estradiol Selectively Enhances Auditory Function in Avian Forebrain Neurons. The Journal of Neuroscience 2012, 32:17597-17611.

Estrogen increased the sensitivity and response strength of neurons in field $L$ to tones and conspecific songs in breeding female, but not male, White-crowned Sparrows. Elevated estrogen in breeding females produces a transient sex difference in auditory discrimination. 
**39. Caras ML, Sen K, Rubel EW, Brenowitz EA: Seasonal Plasticity of Precise Spike Timing in the Avian Auditory System. The Journal of Neuroscience 2015, 35:3431-3445.

In female, but not male, White-crowned Sparrows estrogen increases the proportion of auditory neurons in Field $L$ that encode sound intensity by spike timing.

40. Remage-Healey L, Dong SM, Chao A, Schlinger BA: Sex-specific, rapid neuroestrogen fluctuations and neurophysiological actions in the songbird auditory forebrain. J Neurophysiol 2012, 107:16211631.

*41. Remage-Healey L, Maidment NT, Schlinger BA: Forebrain steroid levels fluctuate rapidly during social interactions. Nature Neuroscience 2008, 11:1327-1334.

This report showed that estrogens can change on a 30-min timescale in the forebrain of awake, behaving zebra finches during social interactions. The work opened a new view of neuroestrogens acting as local and acute neuromodulators in forebrain cognitive circuits.

42. Metzdorf R, Gahr M, Fusani L: Distribution of aromatase, estrogen receptor, and androgen receptor mRNA in the forebrain of songbirds and nonsongbirds. J. Comp. Neurol. 1999, 407:115-129.

43. Saldanha CJ, Coomaralingam L: Overlap and co-expression of estrogen synthetic and responsive neurons in the songbird brain - a double-label immunocytochemical study. General and Comparative Endocrinology 2005, 141:66-75.

44. Acharya KD, Veney SL: Characterization of the G-protein-coupled membrane-bound estrogen receptor GPR30 in the zebra finch brain reveals a sex difference in gene and protein expression. Developmental Neurobiology 2012, 72:1433-1446.

45. Adkins-Regan E, Mansukhani V, Seiwert C, Thompson R: Sexual differentiation of brain and behavior in the zebra finch: critical periods for effects of early estrogen treatment. J Neurobiol 1994, 25:865877. 
46. Holloway CC, Clayton DE: Estrogen synthesis in the male brain triggers development of the avian song control pathway in vitro. Nature Neuroscience 2001, 4:170-175.

47. Grisham W, Lee J, Park SH, Mankowski JL, Arnold AP: A dose-response study of estradiol's effects on the developing zebra finch song system. Neuroscience letters 2008, 445:158-161.

48. McCarthy MM, Arnold AP: Reframing sexual differentiation of the brain. Nat Neurosci 2011, 14:677683.

**49. Chao A, Paon A, Remage-Healey L: Dynamic variation in forebrain estradiol levels during song learning. Developmental Neurobiology 2015, 75:271-286.

In vivo levels of estrogens in the auditory forebrain of Zebra Finches are the same in males and females during the critical period for masculinization of the song nuclei. A sex difference in brain estrogen levels emerges later in development, with higher levels in males as they approach sexual maturity.

50. Bailey DJ, Saldanha CJ: The importance of neural aromatization in the acquisition, recall, and integration of song and spatial memories in passerines. Hormones and Behavior 2015, 74:116-124.

51. Luo M, Ding L, Perkel DJ: An avian basal ganglia pathway essential for vocal learning forms a closed topographic loop. J Neurosci 2001, 21:6836-6845.

52. Olveczky BP, Andalman AS, Fee MS: Vocal experimentation in the juvenile songbird requires a basal ganglia circuit. PLoS biology 2005, 3:e153.

53. Brainard MS: The anterior forebrain pathway and vocal plasticity. In Neuroscience of birdsong. Edited by Zeigler HP, Marler P: Cambridge University Press; 2008:240-255.

54. Hahnloser RHR, Kotowicz A: Auditory representations and memory in birdsong learning. Current Opinion in Neurobiology 2010, 20:332-339.

55. Wild JM, Nils OEK, Kubke MF: Connections of the auditory brainstem in a songbird, Taeniopygia guttata. III. Projections of the superior olive and lateral lemniscal nuclei. The Journal of Comparative Neurology 2010, 518:2149-2167. 


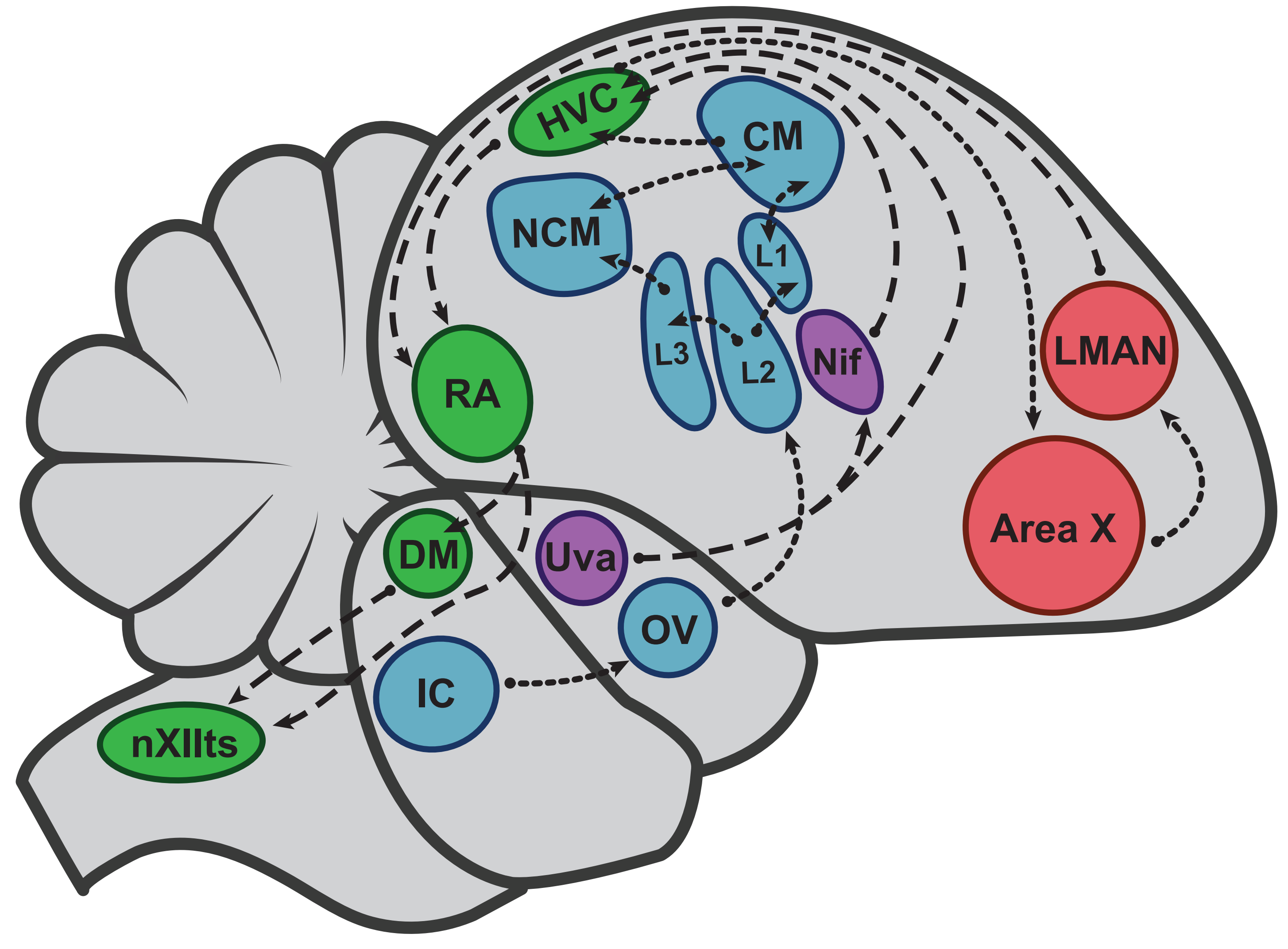

